Submission ID: 43833

\title{
Automated Thermal History Reconstruction of Basin in West Siberia Using
} 2D Inverse Modeling

E. Chekhonin (Skolkovo Institute of Science and Technology), G. Peshkov* (Skolkovo Institute of Science and Technology), A. Myasnikov (Skolkovo Institute of Science and Technology), L. Rupke (GeoModelling Solutions), Y. Podladchikov (University of Lausanne), K. Musikhin (LUKOILEngineering LLC), A. Shuvaev (LUKOIL-Engineering LLC), O. Bogdanov (LUKOIL-Engineering LLC), $O$. Kostenko (LUKOIL-Engineering LLC), P. Maglevannaya (LUKOIL-Engineering LLC), M. Mazitov (LUKOIL-West Siberia LLC), A. Kachkin (LUKOIL-West Siberia LLC)

\section{SUMMARY}

Understanding thermal and structural evolution of sedimentary basin is a key to assessing the hydrocarbon prospect. In the common approach to reconstruction of this evolution, a priori knowledge of thinning factors and paleobathymetry is required (while necessary data is commonly not available), sub-basin crust and mantle lithosphere evolution is omitted, and information about basal heat flow (it is usually getting from published heat flow maps, while this data is highly unreliable) is used as a boundary condition. Automatic correction of the prescribed heat flow is performed to get a good matching of modeling results with measured present-day temperature and maturity indicators. As a result, the approach gives multiple solutions and leads to fluctuations in temperature and maturity without proper physical/geological justification. There is an alternative approach to thermal reconstruction, resolving simultaneously for lithosphere and sedimentary basin processes. It involves an inverse algorithm, which iteratively updates crustal- and mantle-thinning factors and paleowater depth until the input stratigraphy is fitted to desired accuracy. The potential of this approach is demonstrated through comprehensive study of a transect across the West Siberian basin. Different geological scenario was considered, parametric study on key parameters was done, and the thermal blanketing effect of sediments was demonstrated. 
Автоматизированное восстановление тепловой истории бассейна Западной Сибири с использованием инверсного 2D моделирования

Е.М. Чехонин, Г.А. Пешков*, А.В. Мясников (Сколковский институт науки и технологии), Л.Х. Рупке (ГеоМоделинг Сольюшенс), Ю.Ю. Подладчиков (Университет Лозанны), К.В. Мусихин, А.О. Шуваев, О.А. Богданов, О.В. Костенко, П.С. Маглеванная (ООО «ЛУКОЙЛИнжиниринг»), М.Р. Мазитов, А.А. Качкин (ООО «ЛУКОЙЛ-Западная Сибирь»)

\section{Введение}

Восстановление тепловой истории осадочных бассейнов является важным и нетривиальным этапом бассейнового моделирования, требующим, в идеале, интеграции процессов, определяющих термический режим осадочной толщи бассейна, с термической и тектонической историей подстилающей литосферы [Галушкин, 2007; Галушкин и др., 2014; Мясников и др., 2015]. Однако зачастую такую интеграцию не производят, задавая на подошве осадочного слоя (которая отождествляется с нижней границей области счёта) граничное условие в виде пространственного и временного распределения плотности глубинного теплового потока. При этом используют современные карты тепловых потоков, что почти всегда подразумевает наличие значительных ошибок в исходных геотермических данных [Попов, 2015]. Отсутствие надежных данных по тепловым свойствам пород и современным тепловым потокам еще более усложняет задачу восстановления тепловой истории и понижает достоверность полученного решения. Более того, в попытках откалиброваться на известные данные по температуре и/или отражательной способности витринита (ОСВ) вносят изменения в заданный тепловой поток (преимущественно случайным образом), что часто приводит к локальным резким скачкам теплового потока, температуры, ОСВ при отсутствии должного физического обоснования, и подразумевает наличие множества решений задачи [Мусихин и др., 2017]. В результате, такой подход приводит к искаженным оценкам времени начала и пика генерации и миграции углеводородов, степени заполнения ловушек и фазового состава флюидов в прогнозируемых залежах. В то же время, существует альтернативный подход, основанный на задании температуры на нижней границе расчетной области, которая при этом должна быть погружена достаточно глубоко, в нижних слоях литосферы или несколько глубже ее подошвы с захватом верхней части астеносферы [Галушкин и др., 2014]. В этом случае восстановление теплового потока происходит автоматически, что существенно повышает точность моделирования термальной эволюции при прогнозе образования углеводородов [Мясников и др., 2015]. Существенным условием успешной автоматической палеореконструкции теплового потока является математически корректно организованная процедура решения обратной задачи с применением современных методов регуляризации [Rupke et al., 2008; Poplavskii et al., 2001]. Такой подход используется в настоящей работе для восстановления тепловой истории по линии регионального профиля в Западно-Сибирском НГБ.

\section{Условие на нижней границе и инверсное моделирование}

Значительное уменьшение неопределенностей, связанных с некорректным восстановлением тепловой истории, может быть достигнуто с помощью инверсного моделирования [Rupke et al., 2008; Poplavskii et al., 2001], включающего все типичные процессы образования бассейна (осадконакопление, компакцию, разломообразование, производство и перенос тепла, фазовые переходы минералов горных пород, многостадийный рифтинг и т.п.) и позволяющего учитывать регионально изостатический отклик литосферы на нагрузку и разные амплитуды растяжения коры и литосферной мантии (рисунок 1). При этом нижняя граница области счёта служит уровнем изостазии, используемым при расчётах тектонического погружения поверхности фундамента, на которой задают фиксированное значение температуры $\mathrm{T}_{\text {ast }}$ (полагая, что, в силу падения вязкости мантии с ростом температуры, интенсивные конвективные движения приводят к латеральному выравниванию температур). Вариация вертикальных нагрузок вследствие утонения и изменения температуры коры и мантии проецируется на упругую плиту, флексурная жесткость которой зависит от эффективной 


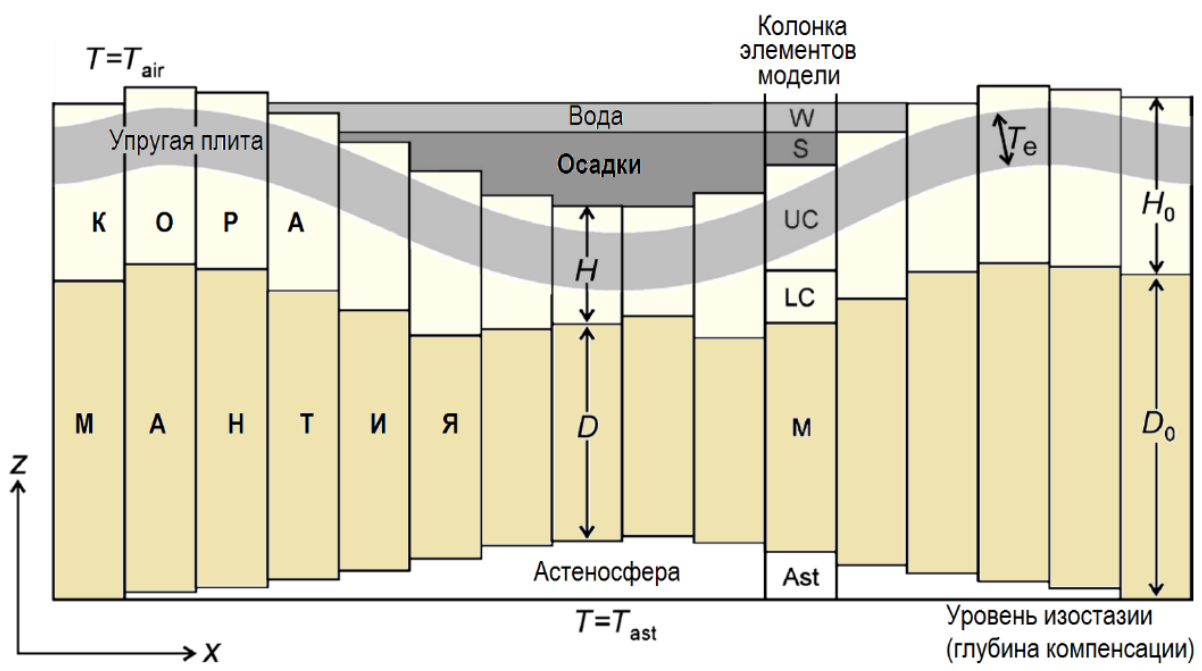

Параметры, уточняемые в процессе решения:

- растяжение коры

$$
\delta(X)=\frac{H_{0}}{H}
$$

- растяжение мантии

$$
\beta(X)=\frac{D_{0}}{D}
$$

- палеоглубина $\mathrm{w}(X, t)$

Рисунок 1. Схематичное изображение бассейновой модели с элементами решения задачи.

толщины $\mathrm{T}_{\mathrm{e}}$, температур на границах модели и т.д. Неизвестные параметры растяжения коры и мантии и палеоглубина воды определяются итерационно в процессе решения задачи из условия близости стратиграфии, вычисленной с предполагаемым набором параметров, к наблюдаемой. При таком подходе наборы известных данных, таких как текущая температура, тепловые потоки, ОСВ и т.П., не являются частью процедуры решения, а используются лишь для проверки качества модели (и уточнения параметров коры и мантии). Совмещение известной информации о геологической истории изучаемого региона с автоматизацией решения математически некорректной обратной задачи по палеореконструкции теплового потока с применением современных методов регуляризации приводит к более достоверным результатам моделирования, чем традиционный подход, допускающий многозначные решения.

\section{Пример автоматизированного восстановления тепловой истории}

В работе продемонстрирован пример использования инверсного моделирования к восстановлению термической истории с использованием программного пакета TecMod2D на $2 \mathrm{D}$ модели, построенной в центральной части Западно-Сибирского НГБ по линии регионального профиля (рисунок 2). Были рассмотрены разные возможные варианты механизма формирования осадочного бассейна (вариант с учетом флексурной изостазии, вариант без учёта флексурной изостазии, вариант, предполагающий равномерное растяжение коры и мантии, и вариант, предполагающий неравномерное утонение коры и мантии),
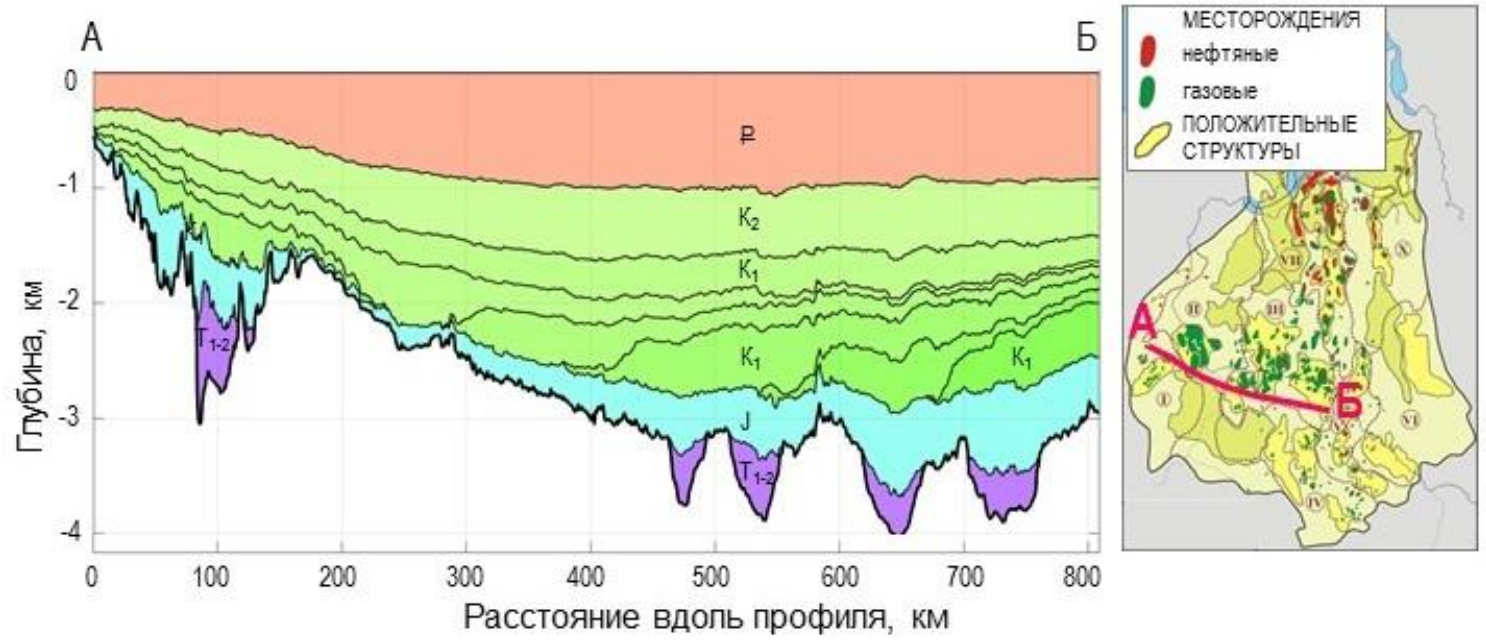

Рисунок 2. Местоположение субмеридианального регионального профиля №6 в ЗападноСибирском НГБ и соответствуюший разрез вдоль линии профиля. 


\section{EAGE}

сопоставлены и проанализированы соответствующие результаты восстановления теплового потока через границу «фундамент-осадочный чехол». Один из результатов приведен на рисунке 3, где явно наблюдается т.н. blanketing effect - эффект понижения теплового потока изза относительно быстрого появления осадков определенной мощности, теплопроводность которых ниже теплопроводности коры (см., например, [Theissen and Rüpke, 2010]), - и постепенное повышение теплового потока в последние десятки млн. лет, связанное со снижением среднегодовых температур на свободной поверхности (и сопровождаемое постепенным снижением температуры в баженовской свите).

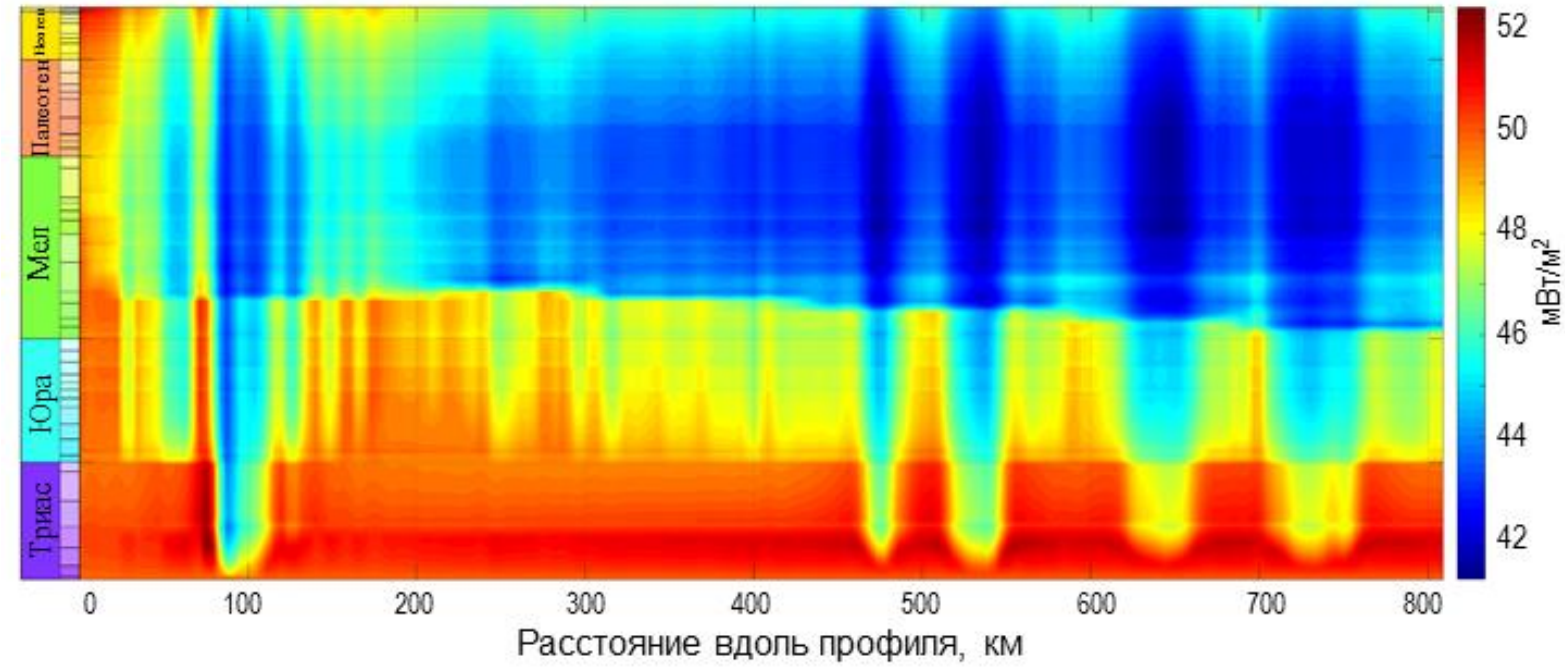

Рисунок 3. Пример палеореконструкиции плотности теплового потока через кровлю фундамента. На рисунке видно, как интенсивное осадконакопление в неокоме подавляет тепловой поток.

В связи с тем, что для моделирования динамики развития литосферы в окрестности бассейна используется ряд исходных параметров, известных с ограниченной точностью (теплофизические свойства пород бассейна, мощности коры и мантии и другие), выполнено параметрическое исследование с целью оценки неопределенности в исходных параметрах модели на результаты моделирования. Показано, что при отсутствии надежных данных по тепловым свойствам пород (типичная неопределенность в которых достигает $80 \%$ и более, см. [Попов, 2015]) вблизи данного разреза, реконструкция с различными наборами тепловых свойств приводит к аналогичным распределениям теплового потока (с максимальной разницей менее $3.5 \mathrm{mBT} / \mathrm{M}^{2}$, см. рисунок 4), но при этом к существенно различному прогнозу температуры (несколько десятков градусов) и ОСВ.

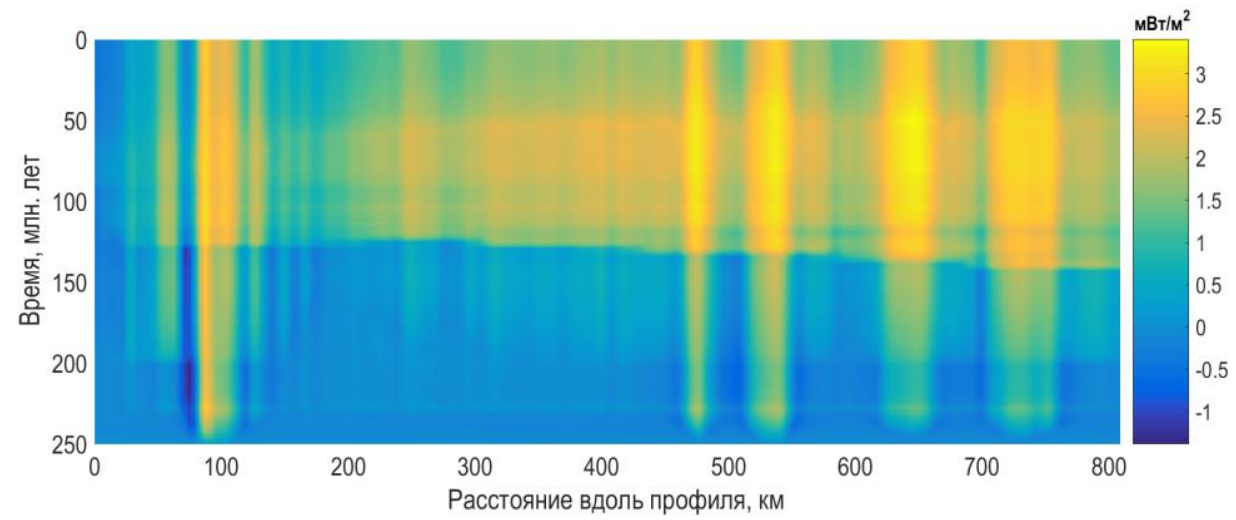

Рисунок 4. Эффект от использования двух различных наборов данных по тепловым свойствам. Цветом показана разница между потоком, восстановленным с максимальными тепловыми свойствами пород осадочного чехла (+30\% от средних значений), и потоком, восстановленным с минимальными тепловыми свойствами (-30\% от средних значений). 
В результате исследования был выбран наиболее вероятный геологический сценарий формирования бассейна (при котором результаты расчёта температуры и ОСВ не противоречат доступному набору данных в скважинах, находящихся в непосредственной близости от профиля № 6), получено пространственное и временное распределение плотности теплового потока через границу «фундамент-осадочный чехол», которое можно использовать как граничное условие снизу при бассейновом моделировании, выполняемого традиционным способом с помощью соответствующего программного обеспечения.

\section{Выводы}

Традиционный подход к восстановлению тепловой истории, не учитывающий термическую и тектоническую историю подстилающей литосферы, приводит к множеству решений, генерируемых без должного физического обоснования.

Значительного уменьшения неопределенностей, связанных с некорректным восстановлением тепловой истории, можно достичь с помощью описанного подхода, совмещающего возможности современного программного обеспечения, знания специалистов о геологической истории изучаемого района и компьютерную автоматизацию решения математически некорректной обратной задачи по палеореконструкции теплового потока с применением современных методов регуляризации. Восстановленную плотность теплового потока можно использовать как граничное условие снизу при бассейновом моделировании в современном программном обеспечении (PetroMod, TemisFlow и пр.).

Типичные ошибки, совершаемые на стадии тепловой палеореконструкции, с учётом отсутствия надежных данных по тепловым свойствам пород и тепловому потоку, могут привести к искажению выводов о процессах генерации и миграции углеводородов, о степени заполнения ловушек и фазовом составе флюидов в прогнозируемых залежах.

\section{Библиография}

Галушкин Ю.И. [2007] Моделирование осадочных бассейнов и оценка их нефтегазогосности. М.: Научный мир, 456 с.

Галушкин Ю.И., Эль Магхби, А., Эль Гтлави, М. [2014] Термический режим и амплитуда растяжения литосферы бассейна Сирт, Ливия - численные оценки в системе моделирования плоских бассейнов. Физика Земли, 2014, № 1, с. 75-88.

Мусихин К.В., Шуваев А.О., Богданов О.А., Костенко О.В., Чехонин Е.М., Пешков Г.А., Мясников А.В. [2017] Учет влияния теплопроводности горных пород на эволюцию НГ-систем на примере баженовской формации Западной Сибири. Международная научно-практическая конференция «ГеоСочи-2017».

Мясников А.В., Подладчиков Ю.Ю. и Попов Ю.А. [2015] Повышение точности моделирования термальной эволюции при прогнозе образования углеводородов. Труды конференции EAGE «Геомодель 2015», Россия, г. Геленджик.

Попов Ю.А. [2015] Проблема качества исходных петротеплофизических и геотермических данных при моделировании осадочных бассейнов и нефтегазоносных систем. Труды конференции EAGE «Геомодель-2015», Россия, г. Геленджик.

Poplavskii' K., Podladchikov Yu., Stephenson R. [2001] Two-dimensional inverse modeling of sedimentary basin subsidence. J. Geophys. Res., 06 (b4), p. 6657-6671.

Rupke L.H., Schmalholz S.M., Schmid E.H., Podladchikov Y. [2008], Automated thermotectonostratigraphic basin reconstruction: Viking Graben case study, AAPG Bull., 92, no. 3, pp. 309-326.

Theissen, S., Rüpke, L.H., [2010] Feedbacks of sedimentation on crustal heat flow: New insights from the Vøring Basin, Norwegian Sea. Basin Research, 22(6): 976-990. 


\section{References}

Galushkin YU.I. [2007] Modelirovaniye osadochnykh basseynov i otsenka ikh neftegazogosnosti. M.: Nauchnyy mir, $456 \mathrm{~s}$.

Galushkin YU.I., El' Magkhbi, A., El' Gtlavi, M. [2014] Termicheskiy rezhim i amplituda rastyazheniya litosfery basseyna Sirt, Liviya - chislennyye otsenki v sisteme modelirovaniya ploskikh basseynov. Fizika Zemli, 2014, № 1, s. 75-88.

Musikhin K.V., Shuvayev A.O., Bogdanov O.A., Kostenko O.V., Chekhonin E.M., Peshkov G.A., Myasnikov A.V. [2017] Uchet vliyaniya teploprovodnosti gornykh porod na evolyutsiyu NG-sistem na primere bazhenovskoy formatsii Zapadnoy Sibiri. Mezhdunarodnaya nauchno-prakticheskaya konferentsiya «GeoSochi-2017».

Myasnikov A.V., Podladchikov YU.YU. i Popov YU.A. [2015] Povysheniye tochnosti modelirovaniya termal'noy evolyutsii pri prognoze obrazovaniya uglevodorodov. Trudy konferentsii EAGE «Geomodel' 2015», Rossiya, g. Gelendzhik.

Popov YU.A. [2015] Problema kachestva iskhodnykh petroteplofizicheskikh i geotermicheskikh dannykh pri modelirovanii osadochnykh basseynov i neftegazonosnykh sistem. Trudy konferentsii EAGE «Geomodel'-2015», Rossiya, g. Gelendzhik.

Poplavskii' K., Podladchikov Yu., Stephenson R. [2001] Two-dimensional inverse modeling of sedimentary basin subsidence. J. Geophys. Res., 06 (b4), p. 6657-6671.

Rupke L.H., Schmalholz S.M., Schmid E.H., Podladchikov Y. [2008], Automated thermotectonostratigraphic basin reconstruction: Viking Graben case study, AAPG Bull., 92, no. 3, pp. 309-326.

Theissen, S., Rüpke, L.H., [2010] Feedbacks of sedimentation on crustal heat flow: New insights from the Vøring Basin, Norwegian Sea. Basin Research, 22(6): 976-990. 